Aucella, F. 42

Bartolini, D. 30

Berrou, J. 14

Brivio, R. 52

Carati, M.L. 52

Casiraghi, E. 52

Ciffolilli, S. 30

Como, G. 52

Corti, D. 52

Fabbrini, P. 52

Galli, F. 30

Genovesi, S. 52

Gesuete, A. 42
Goeksel, T. 26

Grazia, M. 5

Gregorini, G. 52

Hannedouche, T. 1

Heidenreich, S. 26

Krummel, T. 1

Mancini, E. 5

Mann, H. 26

Métivier, F. 14

Niwa, T. 20

Peraldi, M.-N. 14

Perego, A.F. 48
Pieruzzi, F. 52

Piroddi, M. 30

Prencipe, M. 42

Ritzerfeld, M. 26

Santoro, A. 5, 28

Sirtori, S. 52

Stella, A. 52

Toubert, A. 14

Viganò, M.R. 52

Vigilante, M. 42

Xie, W. 26

\title{
Subject Index Vol. 35, Suppl. 2, 2013
}

3-Carboxy-4-methyl-5-propyl-2furanpropionic acid 20

Adsorption 42, 48

AGEs 30

DELETE system 5

Dialysis 30

- membrane 42

- sorbents 48

Free light chains 5

Glycation 30

Hemodialysis 42, 52
Indoxyl sulphate 20

Inflammation 30

Membranes 48

MICA 14

Multiple myeloma 5

Natural killer cell 14

Nitric oxide 30

NKG2D 14

Oxidative stress 14,30
p-Cresyl sulphate 20

Polymethylmethacrylate 5, 14, 20

- membrane(s) 26,52

Protein damage 30

Protein-leaking haemodialysis 20

Proteomics 30

Prurigo nodularis 26

Reactive oxygen species 30

Serum free light chains 52

Uremia 14,30

Uremic pruritus 26

- toxins 26, 30, 42 